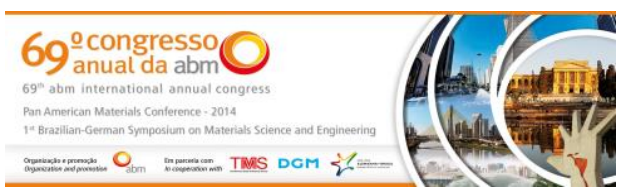

Tema: Soldagem

\title{
EFEITO DA PULSAÇÃO DE CORRENTE SOBRE A MICROESTRUTUA DA ZONA FUNDIDA NA SOLDAGEM DISSIMILAR ENTRE O AÇO INOXIDÁVEL FERRÍTICO AISI 444 E O AÇO INOXIDÁVEL AUSTENÍTICO AISI 316L*
}

\author{
Isabel Ferreira de Barros ${ }^{1}$ \\ Nívea Rodrigues Leite ${ }^{2}$ \\ Hamilton Ferreira Gomes de $\mathrm{Abreu}^{3}$ \\ Cleiton Carvalho Silva ${ }^{4}$
}

\section{Resumo}

O objetivo deste trabalho é investigar o efeito da pulsação de corrente sobre a microestrutura da zona fundida de soldas dissimilares entre o aço inoxidável ferrítico AISI 444 e o austenítico AISI 316L. Chapas dos referidos aços foram unidas pelo processo de soldagem TIG. As soldagens foram realizadas variando-se a frequência de pulsação de 2 a $8 \mathrm{~Hz}$ e sem pulsação, mantendo-se constante a energia de soldagem. A caracterização microestrutural foi realizada por meio de microscopia óptica, MEV, EDS e EBSD. Os resultados mostraram haver um efeito da frequência de pulsação sobre a homogeneidade e microestrutura final da zona fundida.

Palavras-chave: Soldagem TIG; Corrente pulsada; Aços inoxidáveis.

\section{EFFECT OF PULSED CURRENT ON MICROESTRUCTURE OF FUSION ZONE IN DISSIMILAR WELDING BETWEEN AISI 444 FERRITIC STAINLESS STEEL AND AISI 316L AUSTENITIC STAINLESS STEEL}

\section{Abstract}

The objective of this study is to investigate the effect of pulse current on the microstructure of the fusion zone of dissimilar welds between the AISI 444 ferritic stainless steel and AISI 316 L austenitic steel. Thin plates of the respective steels were joint by the TIG process. The welds were made varying the pulse frequency from 2 to 8 and without pulse, maintaining constant the heat input. The characterization of the microstructure was performed using the techniques of optical microscopy, MEV, EDS and EBSD. The results demonstrated that there was an effect of pulsed frequency on homogeneity and final microstructure in the fusion zone.

Keywords: TIG Welding; Pulsed current; Stainless steels.

1 Mestre em Engenharia e Ciência dos Materiais, Universidade Federal do Ceará, Fortaleza, CE, Brasil.

2 Graduanda em Engenharia Metalúrgica, Universidade Federal do Ceará, Fortaleza, CE, Brasil.

3 Doutor em Engenharia Metalúrgica e de Materiais, Professor, Departamento de Engenharia Metalúrgica e de Materiais, Universidade Federal do Ceará, Fortaleza, CE, Brasil.

4 Doutor em Engenharia e Ciência dos Materiais, Professor, Departamento de Engenharia Metalúrgica e de Materiais, Universidade Federal do Ceará, Fortaleza, CE, Brasil.

\footnotetext{
* Technical contribution to the $69^{\text {th }}$ ABM International Annual Congress and to the ENEMET, July $21^{\text {st }}$ 25 $5^{\text {th }}$ 2014, São Paulo, SP, Brazil.
} 


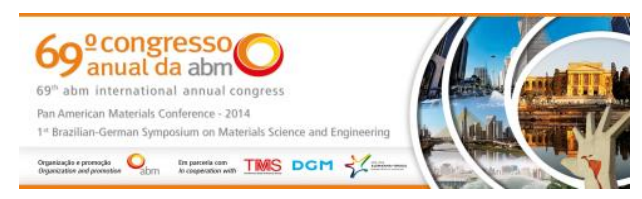

\section{INTRODUÇÃO}

A utilização dos aços inoxidáveis tem se intensificado juntamente com a crescente demanda industrial, em que sua aplicação se estende pelos mais variados setores, como por exemplo, na indústria de petróleo e gás, em equipamentos de dessalinização, na indústria sucroalcooleira, entre outros. Neste contexto, os aços inoxidáveis austeníticos são amplamente utilizados na construção de equipamentos e componentes devido às suas elevadas propriedades mecânicas e de resistência à corrosão. Estes aços possuem em sua composição química a adição de níquel, que por sua vez confere uma microestrutura austenítica e propriedades importantes, como boa ductilidade e tenacidade. Por outro lado, esta adição do Ni torna o aço mais caro e apesar deste elevado custo, ainda tem sido utilizado em situações nas quais muitas vezes não se tem necessidade.

Estudos revelam que em algumas aplicações o uso de aços inoxidáveis austeníticos pode não conferir vantagens devido à baixa exigência de propriedades mecânicas e/ou resistência à corrosão. Desta forma, em determinadas aplicações, os aços inoxidáveis ferríticos podem substituí-los parcialmente sem causar prejuízos nas propriedades mecânicas e de corrosão, principalmente em ambientes propícios à corrosão sob tensão [1-3].

Objetivando estudar a soldagem dissimilar entre o aço inoxidável austenítico AISI 316L e o aço inoxidável ferrítico AISI 444 utilizando o processo TIG autógeno com corrente pulsada e visando avaliar possíveis efeitos de agitação da poça de metal líquido, e uma consequente homogeneização da estrutura, um estudo sistemático sobre o tema tem sido proposto [4]. Portanto, o presente estudo investigou a soldagem dissimilar entre o aço inoxidável ferrítico AISI 444 e o aço inoxidável austenítico AISI 316L, por meio do processo TIG autógeno com corrente pulsada.

\section{MATERIAL E MÉTODOS}

Foram utilizadas chapas do aço inoxidável ferrítico AISI 444 e do aço inoxidável austenítico AISI 316L, ambas com $2 \mathrm{~mm}$ de espessura e dimensões de $210 \times 70$ $\mathrm{mm}$. A composição química dos aços obtida por meio de análise química é apresentada na Tabela 1.

Tabela 1. Composição química dos aços AISI 444 e AISI 316L (\% em peso)

\begin{tabular}{ccccccccc}
\hline Aço & \multicolumn{10}{c}{ Composição Química } \\
Inoxidável & $\mathrm{C}$ & $\mathrm{Mn}$ & $\mathrm{Si}$ & $\mathrm{Cr}$ & $\mathrm{Ni}$ & $\mathrm{Mo}$ & $\mathrm{Nb}$ & $\mathrm{Ti}$ \\
AISI 444 & 0,018 & 0,16 & 0,54 & 17,90 & 0,25 & 1,75 & 0,30 & 0,17 \\
AISI 316L & 0,013 & 1,31 & 0,58 & 16,52 & 10,45 & 2,15 & 0,06 & 0,00 \\
\hline
\end{tabular}

Utilizou-se uma fonte de soldagem multiprocesso e uma mesa com coordenadas $X Y$, contando com um sistema de aquisição dos dados de tensão e corrente de soldagem. Foi usado eletrodo de tungstênio do tipo toriado com diâmetro de $2,4 \mathrm{~mm}$, ajustado na polaridade negativa. Argônio puro foi usado como gás de proteção e também como gás de purga.

Para a realização do presente estudo foi utilizada uma metodologia segmentada em três etapas: testes preliminares para ajuste dos parâmetros, soldagem definitiva, em

\footnotetext{
* Contribuição técnica ao 69 Congresso Anual da ABM - Internacional e ao 14ํㅡㄹ ENEMET - Encontro Nacional de Estudantes de Engenharia Metalúrgica, de Materiais e de Minas, 21 a 25 de julho de 2014, São Paulo, SP, Brasil.
} 


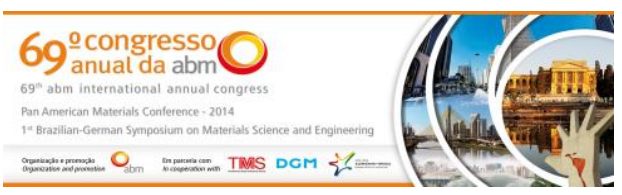

que foram utilizados os parâmetros definidos para realizar a soldagem em um único passe com penetração total e, por fim, a caracterização microestrutural para análise das diversas regiões da solda, zona fundida e ZAC.

Inicialmente foi necessário realizar um estudo exploratório dos principais parâmetros a serem ajustados com base no trabalho realizado por Mendes [5], para posteriormente aplica-los durante as soldagens definitivas. Dentre os parâmetros definidos, pode-se citar a velocidade de soldagem $(15 \mathrm{~cm} / \mathrm{min})$, a vazão do gás de proteção (20 l/min) e a distância do eletrodo à peça $(2 \mathrm{~mm})$. A Tabela 2 apresenta os parâmetros utilizados durante as soldagens definitivas.

Tabela 2. Parâmetros de soldagem TIG com pulsação da corrente

\begin{tabular}{cccccc}
\hline Parâmetros/ Amostra & F0 & F2 & F4 & F6 & F8 \\
\hline Corrente de base (lb) (A) & - & 30 & 30 & 30 & 30 \\
\hline Corrente de pico (lp) (A) & 72 & 197 & 196 & 196 & 196 \\
\hline$\%$ Tempo de pico & $100 \%$ & $20 \%$ & $20 \%$ & $20 \%$ & $20 \%$ \\
\hline Tempo de base (tb) (s) & - & 0,4 & 0,2 & 0,1333 & 0,1 \\
\hline Tempo de pico (tp) (s) & - & 0,1 & 0,05 & 0,0333 & 0,025 \\
\hline Frequência de pulso (Hz) & 0 & 2 & 4 & 6 & 8 \\
\hline Corrente Eficaz (A) & 72 & 92,10 & 91,67 & 91,67 & 91,67 \\
\hline Corrente Média (A) & 72 & 63,40 & 63,20 & 63,20 & 63,20 \\
\hline Tensão $(\mathrm{V})$ & 14 & 12 & 12 & 12 & 12 \\
\hline Energia $(\mathrm{KJ} / \mathrm{cm})$ & 4,03 & 4,42 & 4,40 & 4,40 & 4,40 \\
\hline
\end{tabular}

Após as soldagens definitivas, realizou-se a caracterização microestrutural. Para isto, as amostras foram submetidas ao corte e à preparação metalográfica, seguindo as etapas de lixamento e polimento mecânico em pasta de diamante ( $3 \mu \mathrm{m}$ e $1 \mu \mathrm{m})$ e alumina $(1 \mu \mathrm{m}$ e $0,05 \mu \mathrm{m})$. Entretanto, como no conjunto soldado há o aço inoxidável ferrítico houve a necessidade de realizar um polimento automático utilizando uma solução composta por sílica coloidal e água Mili-Q durante 1 hora para obtenção de uma superfície com melhor acabamento. Tal preparação foi necessária para a realização das análises microestruturais, bem como EBSD.

Como a liga obtida a partir da soldagem dissimilar é composta por dois metais de base distintos, houve a necessidade de revelar ambas as microestruturas. Contudo, não foi possível obter a melhor condição de contraste/revelação utilizando apenas um reagente. Por este motivo, foram testadas diversas combinações e sequências de ataque químico. Desta forma, a sequência de ataque que melhor revelou a estrutura foi o reagente Behara aquecido a $60^{\circ} \mathrm{C}(23 \mathrm{~mL}$ de $\mathrm{HCl}+77 \mathrm{~mL}$ de água destilada $+0,35 \mathrm{~g}$ de metabissulfito de potássio $\left.\left(\mathrm{K}_{2} \mathrm{~S}_{2} \mathrm{O}_{5}\right)\right)$ com o reagente $\mathrm{HNO}_{3}$ (40\% de ácido nítrico diluído em $60 \%$ de água destilada). Para a análise dos resultados obtidos nas soldagens e identificação das microestruturas foram utilizadas as técnicas de microscopia óptica (MO), microscopia eletrônica de varredura (MEV), espectroscopia de energia dispersiva de raios-X (EDS) e difração de elétrons retroespalhados (EBSD).

\section{RESULTADOS}

\footnotetext{
* Contribuição técnica ao 69 Congresso Anual da ABM - Internacional e ao 14ํㅡㄹ ENET - Encontro Nacional de Estudantes de Engenharia Metalúrgica, de Materiais e de Minas, 21 a 25 de julho de 2014, São Paulo, SP, Brasil.
} 


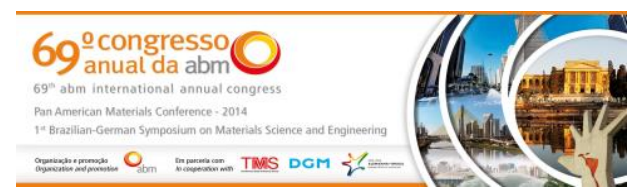

A microestrutura do metal de base do aço inoxidável ferrítico AISI 444 é constituída por grãos de ferrita poligonais, como pode ser observado na Figura 1.

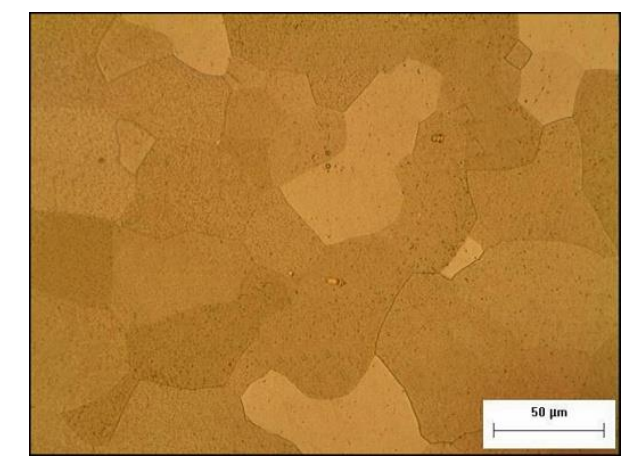

Figura 1. Metal de base do aço inoxidável ferrítico AISI 444.

A microestrutura do metal de base do aço inoxidável austenítico AISI $316 \mathrm{~L}$ é constituída por grãos equiaxiais de austenita juntamente com a presença de grãos de ferrita $\delta$ alongados no sentido de laminação da chapa, podendo ainda conter algum carboneto precipitado, conforme apresentado na Figura 2.

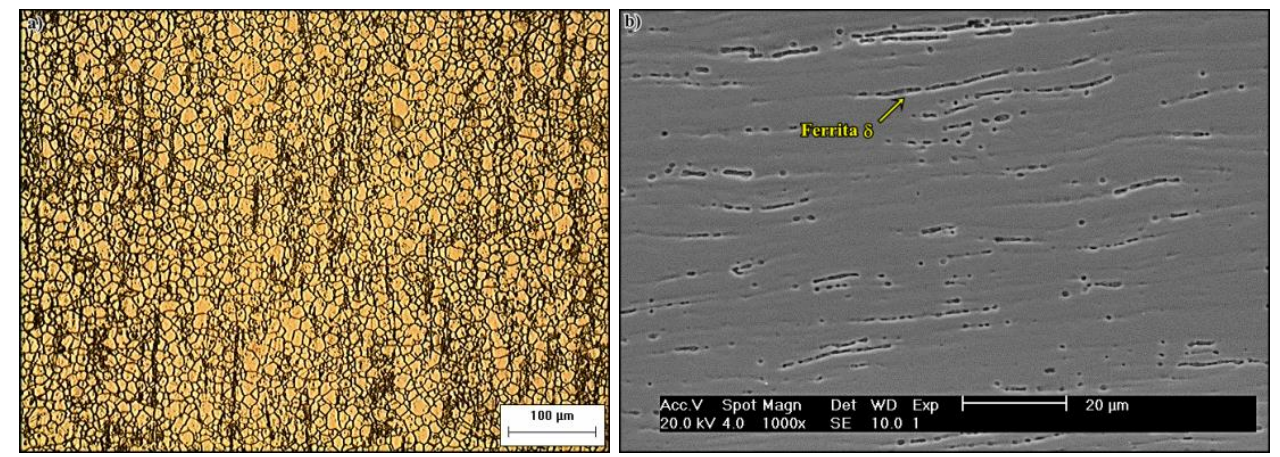

Figura 2. Metal de base do aço inoxidável austenítico AISI 316L. a) Microestrutura do metal de base obtida por $\mathrm{MO}$ (Reagente $\mathrm{HNO}_{3}$, aumento 200x). b) Microestrutura do metal de base apresentando ferrita $\delta$ obtida por MEV.

Durante as soldagens dissimilares definitivas foi observada a ocorrência do fenômeno da deflexão magnética, desviando o arco em direção ao aço inoxidável ferrítico AISI 444. Aparentemente, este fenômeno foi mais intenso para as soldagens utilizando frequências de pulsação mais baixas $(0 \mathrm{~Hz}, 2 \mathrm{~Hz}$ e $4 \mathrm{~Hz})$, as quais originaram zonas fundidas com grãos grosseiros e predominantemente ferríticos. Além dos grãos ferríticos, houve para estas condições uma intensa formação de estruturas agulhadas decorando os contornos dos grãos ferríticos. Estas características microestruturais pode estar associada à fusão mais intensa do aço inoxidável ferrítico, bem como evidenciar uma menor homogeneidade da composição química na zona fundida. A Figura 3 apresenta as montagens das seções transversais dos corpos de prova soldados com as referidas frequências.

\footnotetext{
* Contribuição técnica ao 69 Congresso Anual da ABM - Internacional e ao 14ํㅡㄹ ENEMET - Encontro Nacional de Estudantes de Engenharia Metalúrgica, de Materiais e de Minas, 21 a 25 de julho de 2014, São Paulo, SP, Brasil.
} 

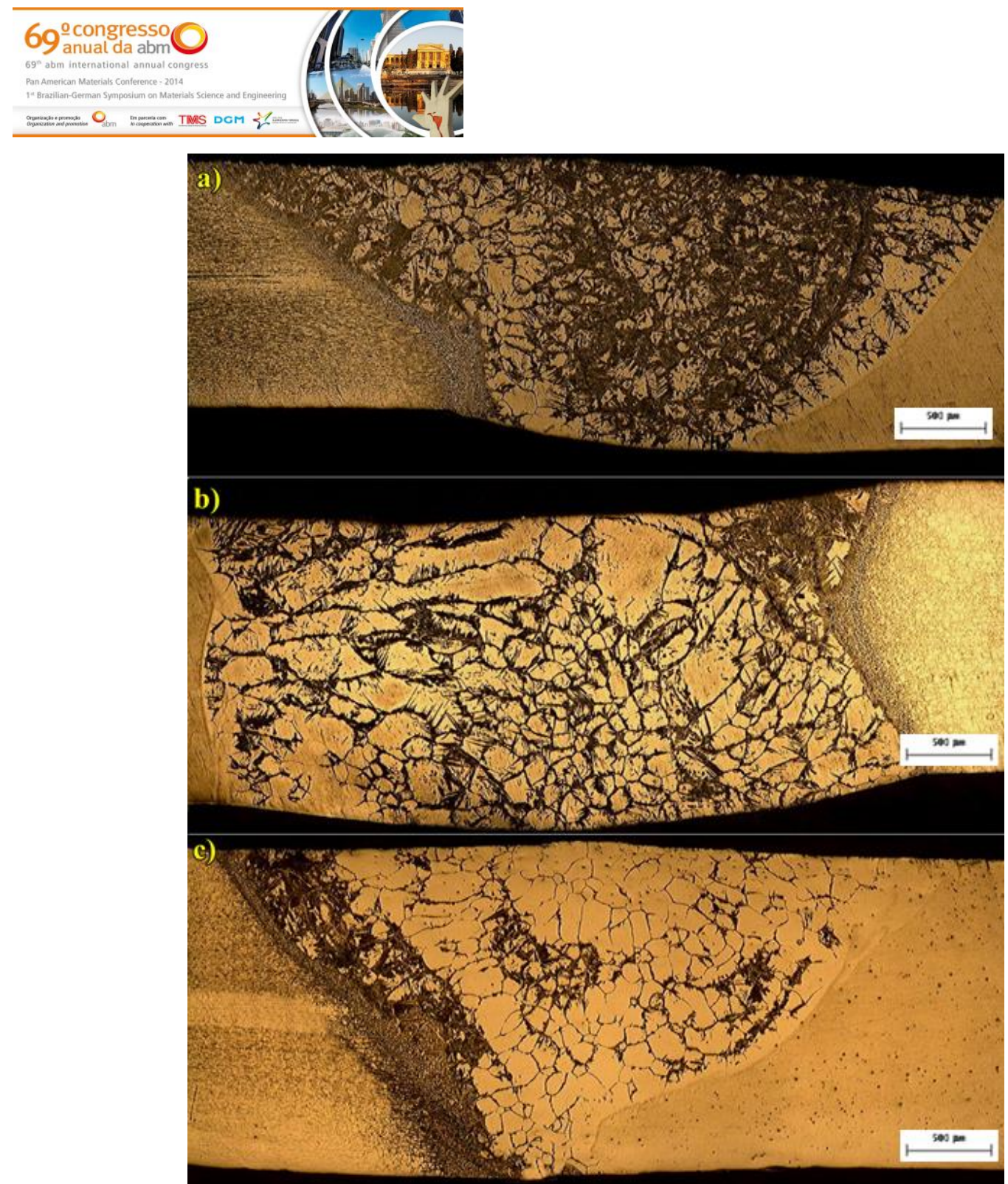

Figura 3. Montagem das amostra dissimilares soldadas com frequências a) $0 \mathrm{~Hz}$, b) $2 \mathrm{~Hz}$ e c) $4 \mathrm{~Hz}$. (Ataque: Behara aquecido a $60^{\circ} \mathrm{C}$ e $\mathrm{HNO}_{3}$ ).

Com auxílio do diagrama pseudo-binário $\mathrm{Fe}-\mathrm{Cr}-\mathrm{Ni}$, apresentado na Figura 4, é possível verificar que para a composição da zona fundida considerando misturas entre os aços variando entre $30 \%$ a $70 \%$, o modo de solidificação é completamente ferrítico, ocorrendo posteriormente transformação no estado sólido de ferrita em austenita.

A fim de analisar a microestrutura e a composição química local da zona fundida das amostras soldadas com frequências de pulsação mais baixas $(0 \mathrm{~Hz}, 2 \mathrm{~Hz}$ e $4 \mathrm{~Hz})$, foram realizadas análises pelas técnicas de MEV e EDS. Tais análises permitiram verificar que a microestrutura resultante nesta região é constituída por grãos de ferrita com austenita e/ou martensita nos contornos de grão.

\footnotetext{
* Contribuição técnica ao $69^{\circ}$ Congresso Anual da ABM - Internacional e ao 14ํㅡㄹ ENEMET - Encontro Nacional de Estudantes de Engenharia Metalúrgica, de Materiais e de Minas, 21 a 25 de julho de 2014, São Paulo, SP, Brasil.
} 

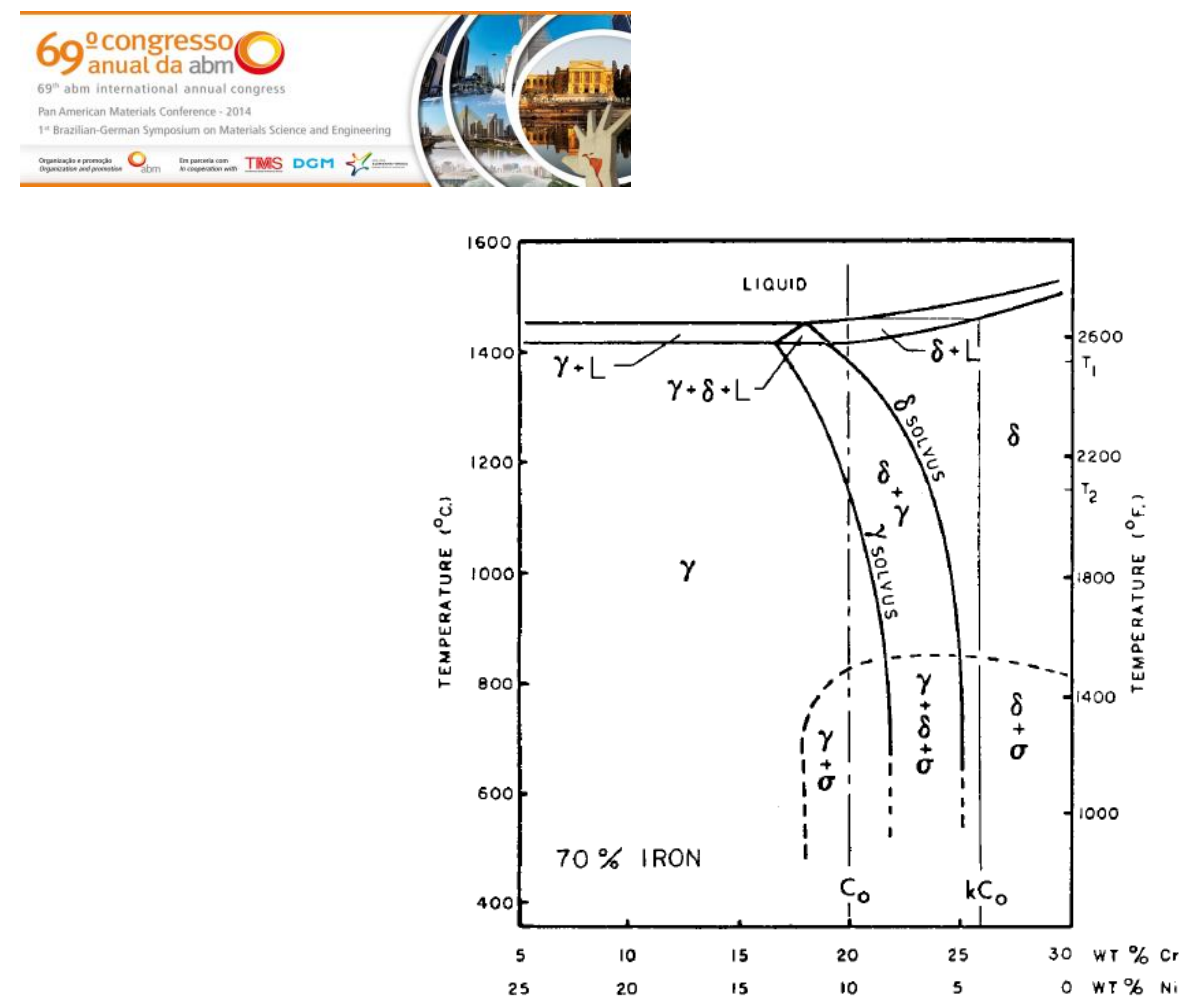

Figura 4. Diagrama pseudobinário do sistema ternário Fe-Cr-Ni para 70\% de Fe [6].

Observou-se que devido à maior concentração de elementos ferritizantes, menor concentração de elementos austenitizantes e aparente menor homogeneidade microestrutural, a presença de maiores volumes de austenita ocorreram preferencialmente no lado da zona fundida próximo ao aço inoxidável austenítico AISI 316L, principalmente devido à maior quantidade de elementos austenitizantes, como por exemplo, o níquel. Entretanto, próximo ao aço inoxidável ferrítico AISI 444, observou-se a presença de microestrutura predominantemente martensítica. A presença da martensita próxima ao aço AISI 444 deve-se ao baixo teor de elementos austenitizantes nesta porção da zona fundida, fazendo com que a austenita formada em alta temperatura não alcance condições de estabilidade suficientes para a sua manutenção à temperatura ambiente, resultando na sua transformação em martensita durante o resfriamento.

A martensita foi identificada tanto pela composição química local quanto pelo ataque químico utilizado, o qual resulta na corrosão do grão da fase martensítica. Para verificar a estabilidade da austenita na microestrutura da zona fundida em função da sua composição química, calculou-se a temperatura de início de transformação martensítica $\left(\mathrm{Mi}_{\mathrm{i}}\right)$ com base em medidas de EDS. A temperatura de transformação martensítica pode ser calculada tomando como referência a Equação 1 [7]:

$$
\mathrm{M}_{\mathrm{i}}\left({ }^{\circ} \mathrm{C}\right)=540-497(\% \mathrm{C})-6,3(\% \mathrm{Mn})-36,3(\% \mathrm{Ni})-10,8(\% \mathrm{Cr})-46,6(\% \mathrm{Mo})
$$

O cálculo do $M_{i}$ para as microestruturas indicadas na Figura 5 evidenciou a transformação martensítica no contorno de grão ferrítico, visto que a temperatura Mi destes grãos foi de aproximadamente $111^{\circ} \mathrm{C}$. A austenita também presente no contorno dos grãos ferríticos pode ser verificada por meio da Figura 6 e o $\mathrm{Mi}$ calculado foi de $-14^{\circ} \mathrm{C}$, confirmando a ausência de transformação martensítica.

\footnotetext{
* Contribuição técnica ao $69^{\circ}$ Congresso Anual da ABM - Internacional e ao 14ํㅡㄹ ENEMET - Encontro Nacional de Estudantes de Engenharia Metalúrgica, de Materiais e de Minas, 21 a 25 de julho de 2014, São Paulo, SP, Brasil.
} 

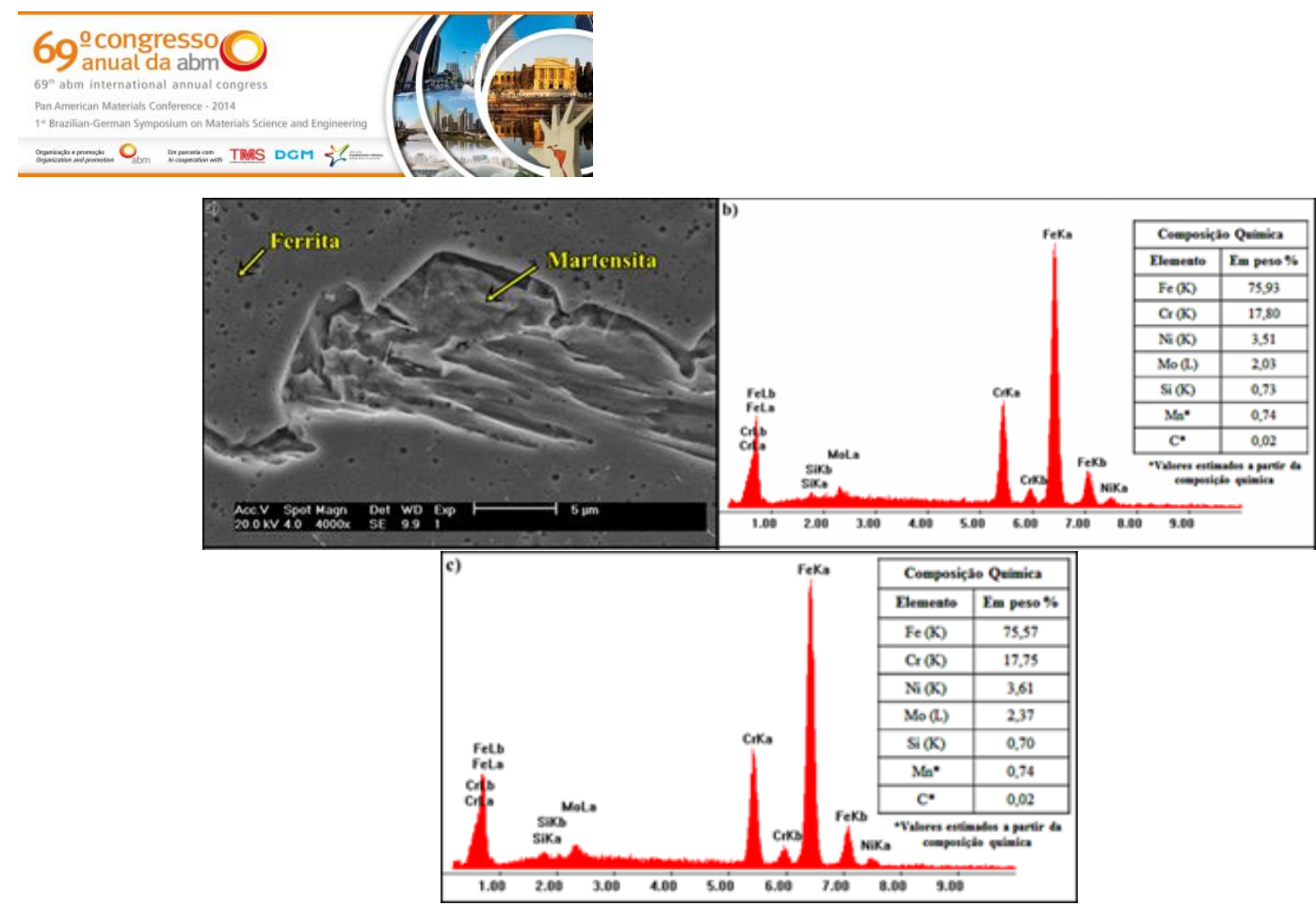

Figura 5. Análise por meio de MEV e EDS da microestrutura da zona fundida da amostra dissimilar soldada com frequência F0 (1). a) Imagem de MEV da microestrutura composta por martensita e ferrita; b) Análise química por EDS sobre o grão de martensita e c) Análise química por EDS sobre o grão ferrítico.
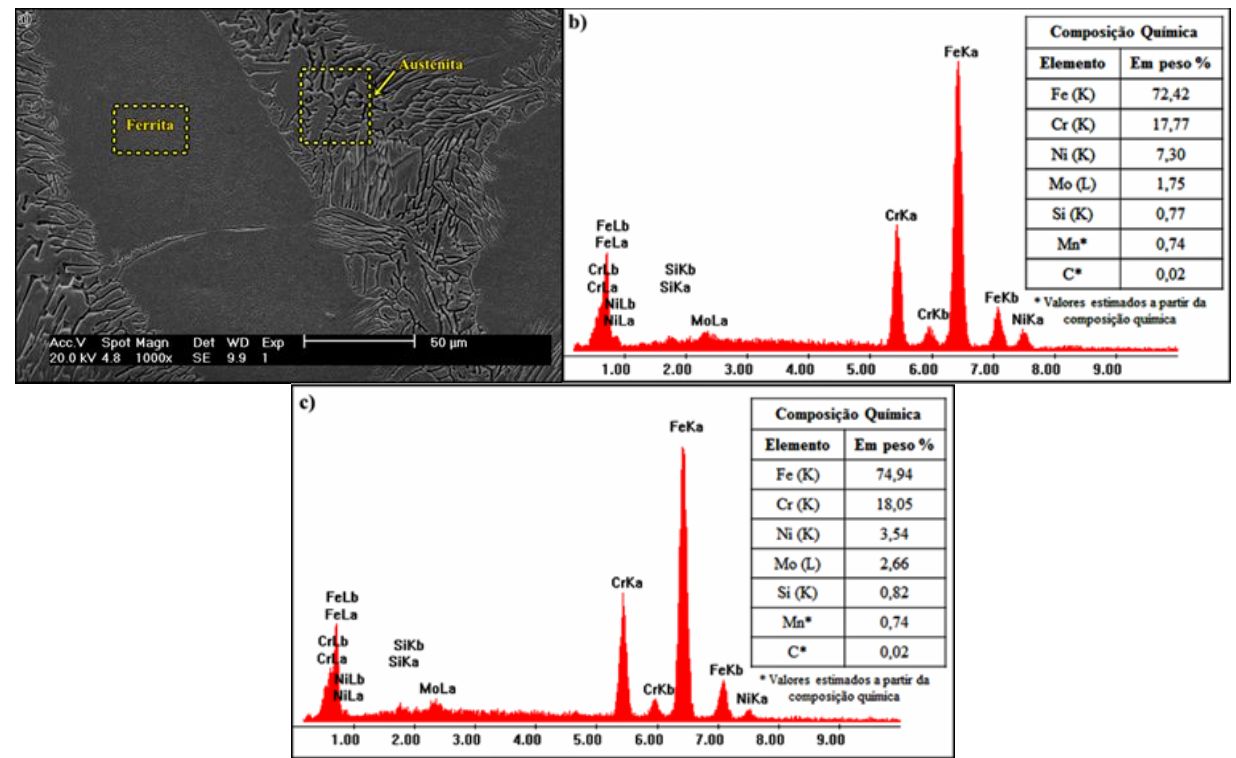

Figura 6. Análise por meio de MEV e EDS da microestrutura da zona fundida da amostra dissimilar soldada com frequência F0 (2). a) Imagem de MEV da microestrutura composta por austenita e ferrita; b) Análise química por EDS sobre o grão de austenita e c) Análise química por EDS sobre o grão ferrítico.

Foram realizadas análises utilizando a técnica de EBSD para auxiliar na confirmação com maior precisão da microestrutura resultante da zona fundida das amostras soldadas com frequências de pulsação mais baixas. A Figura 7 apresenta a imagem do padrão de qualidade e o mapa de fases obtida para a amostra soldada com frequência de $0 \mathrm{~Hz}$.

\footnotetext{
* Contribuição técnica ao $69^{\circ}$ Congresso Anual da ABM - Internacional e ao 14ํㅡㄹ ENEMET - Encontro Nacional de Estudantes de Engenharia Metalúrgica, de Materiais e de Minas, 21 a 25 de julho de 2014, São Paulo, SP, Brasil.
} 

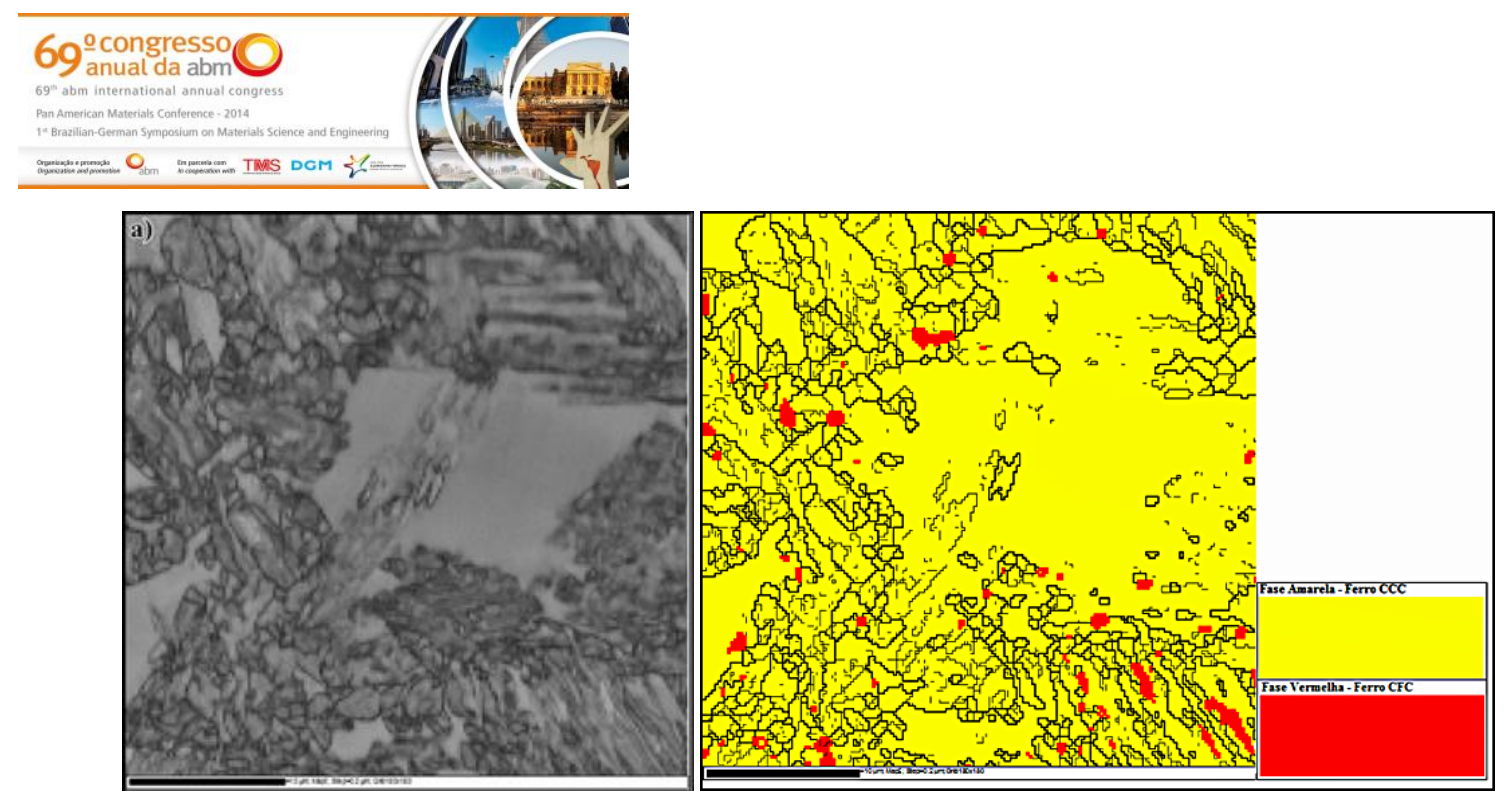

Figura 7. Análise de EBSD da região da zona fundida da amostra dissimilar F0. a) Imagem do padrão de qualidade (EBSD); b) Mapa de fases.

Esta análise permitiu confirmar a presença de ferrita, martensita e austenita na zona fundida das amostras, sendo esta última em menor proporção. No entanto, é fundamental destacar que devido o baixo teor de carbono presente na composição química de ambos os aços, a estrutura cristalina tetragonal de corpo centrado da martensita pode ser facilmente confundida com a estrutura cúbica de corpo centrado da ferrita. Isto ocorre porque a razão c/a da estrutura cristalina TCC tende a 1, que é a razão para a estrutura CCC. Por este motivo, a martensita presente nesta região não pôde ser identificada em sua plenitude pelo software utilizado pelo EBSD. Por este motivo, na identificação das fases somente foram selecionadas as fases ferríta e austenita, sendo os grãos de martensita identificados também como ferrita.

Contudo, foi observado através da Figura $7 \mathrm{~b}$ que análise permitiu identificar pequenas quantidades de austenita retida nos contorno de grão ferrítico e entre os grãos de martensita. Estes pequenos grãos de austenita retida são o resultado de heterogeneidades químicas entre os grãos de austenita em alta temperatura, fazendo com que alguns grãos consigam enrriquecer em elementos austenitizandes o suficiente para garantir sua estabilidade à temperatura ambiente.

A utilização de frequências mais elevadas durante a soldagem, $6 \mathrm{~Hz}$ e $8 \mathrm{~Hz}$, permitiu conferir à zona fundida das amostras dissimilares uma maior homogeneidade da microestrutura quando comparado às soldagens com frequências $0 \mathrm{~Hz}, 2 \mathrm{~Hz}$ e $4 \mathrm{~Hz}$. Observou-se que o aumento da frequência de pulsação conferiu à zona fundida um perfil mais uniforme, com maior participação do aço inoxidável austenítico para compor a zona fundida, bem como uma aparente maior homogeneidade. Tais características estão associadas ao maior controle do arco elétrico. A Figura 8 apresenta as montagens das seções transversais dos corpos de prova soldados com frequências de 6 e $8 \mathrm{~Hz}$, respectivamente.

\footnotetext{
* Contribuição técnica ao 69 Congresso Anual da ABM - Internacional e ao 14ํㅡㄹ ENEMET - Encontro Nacional de Estudantes de Engenharia Metalúrgica, de Materiais e de Minas, 21 a 25 de julho de 2014, São Paulo, SP, Brasil.
} 

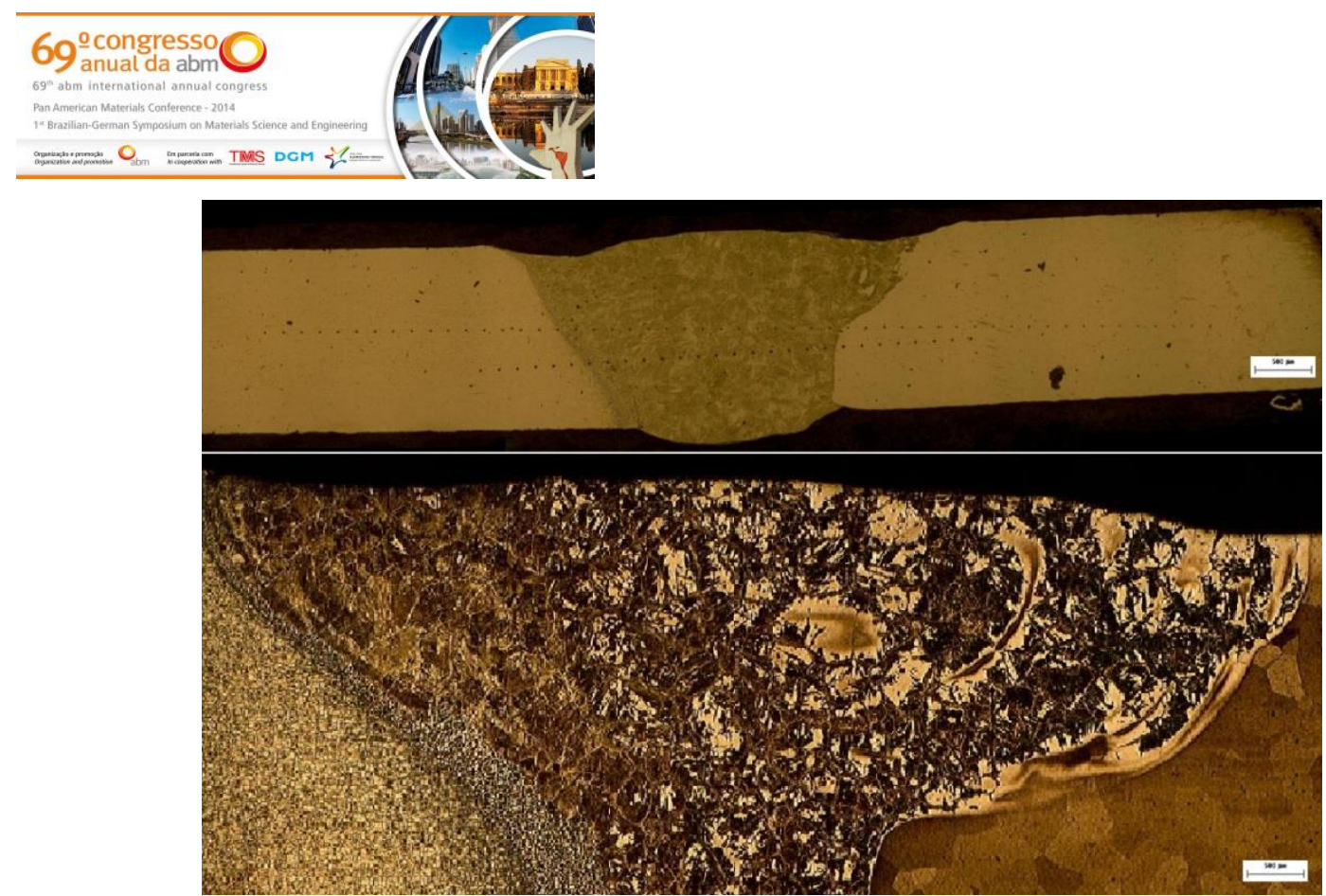

Figura 8. Montagem das amostras dissimilares soldadas com frequência a) $6 \mathrm{~Hz}$ e b) $8 \mathrm{~Hz}$. (Ataque: Behara aquecido a $60^{\circ} \mathrm{C}$ e $\mathrm{HNO}_{3}$ ).

A homogeneidade resultante é característica de uma maior mistura dos materiais utilizados durante a soldagem, possibilitando obter uma zona fundida com microestruturas tipicamente duplex, como por exemplo, austenita alotriomórfica de contorno de grão, intragranular e de Widmanstätten, conforme apresentado na Figura 9.

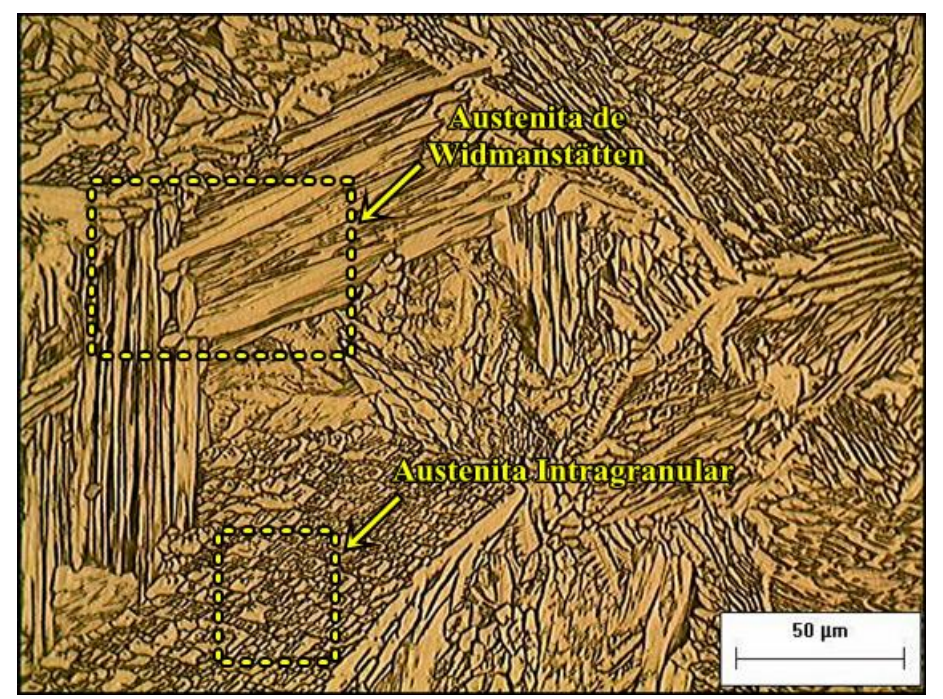

Figura 9. Microestrutura típica duplex apresentada na zona fundida da amostra dissimilar soldada com frequência F6. (Reagente Behara aquecido a $60^{\circ} \mathrm{C}$ e $\mathrm{HNO}_{3}$; aumento de $500 \mathrm{X}$ ).

A Figura 10 apresenta a microestrutura duplex observada na zona fundida da amostra soldada com frequência de $6 \mathrm{~Hz}$. Verifica-se a ausência de martensita ao calcular a Mi equivalente às microestruturas austenítica de Widmanstätten e ferrítica

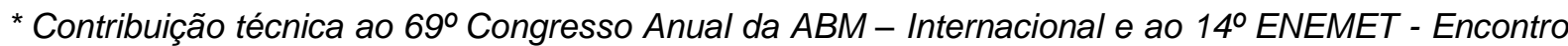
Nacional de Estudantes de Engenharia Metalúrgica, de Materiais e de Minas, 21 a 25 de julho de 2014, São Paulo, SP, Brasil.
} 

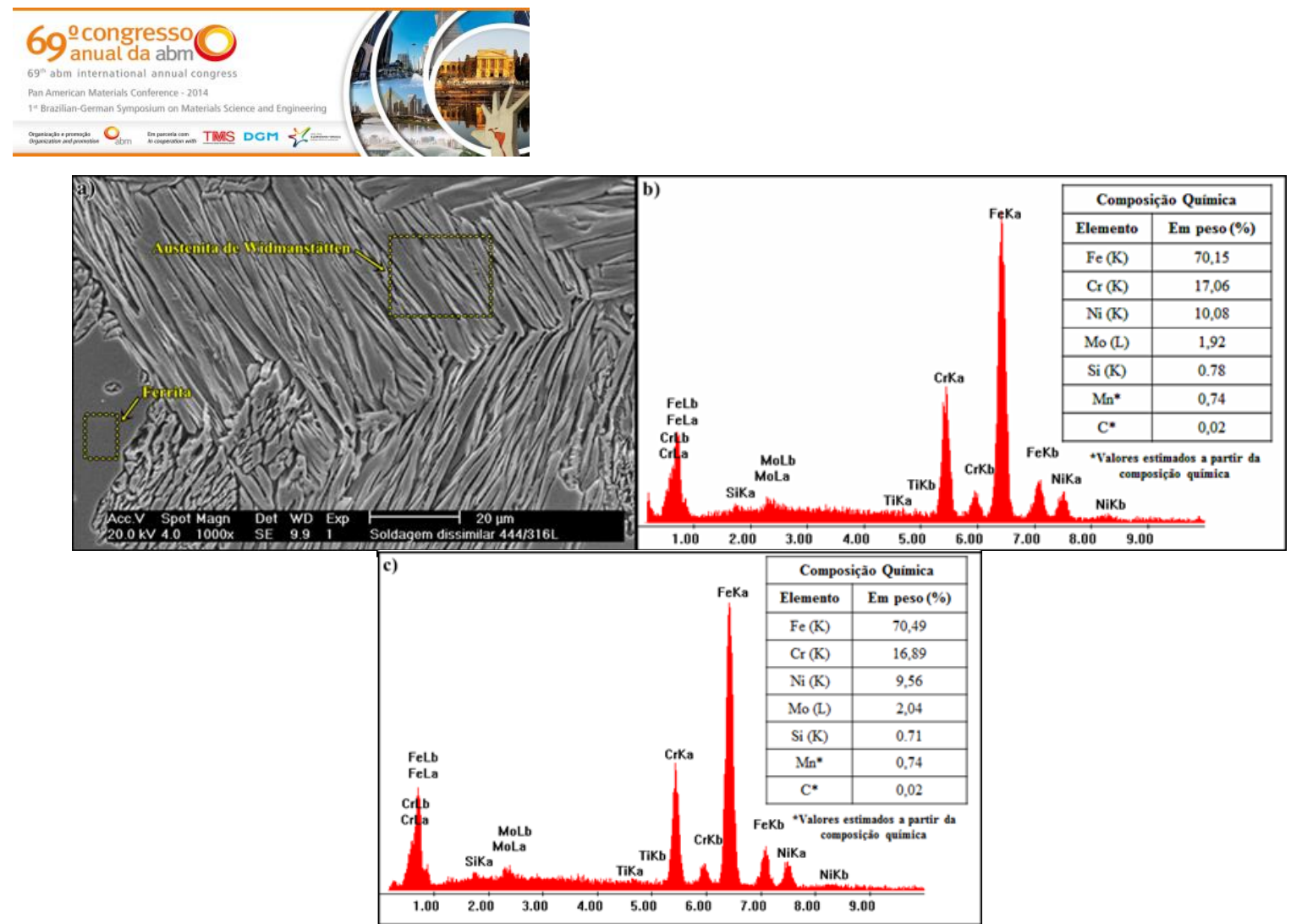

Figura 10. Análise por meio de MEV e EDS da microestrutura da zona fundida da amostra dissimilar soldada com frequência F6. a) Imagem de MEV da microestrutura composta por austenita e ferrita; b) Análise química por EDS da microestrutura austenítica e c) Análise química por EDS da microestrutura ferrítica.

Para auxiliar na confirmação com maior precisão da microestrutura resultante na zona fundida das amostras soldadas com frequências de 6 e $8 \mathrm{~Hz}$, foram construídos mapas das fases por meio de EBSD. O mapa obtido para a amostra soldada com frequência de $6 \mathrm{~Hz}$ é apresentado na Figura 11. Observa-se que diferentemente do apresentado no mapa de orientação da amostra dissimilar soldada com frequência de $0 \mathrm{~Hz}$, o mapa apresentado na Figura $12 \mathrm{~b}$ identificou todas as fases presentes na zona fundida da referida amostra, apresentando uma microestrutura típica duplex, confirmando que havia somente a presença de austenita e ferrita.

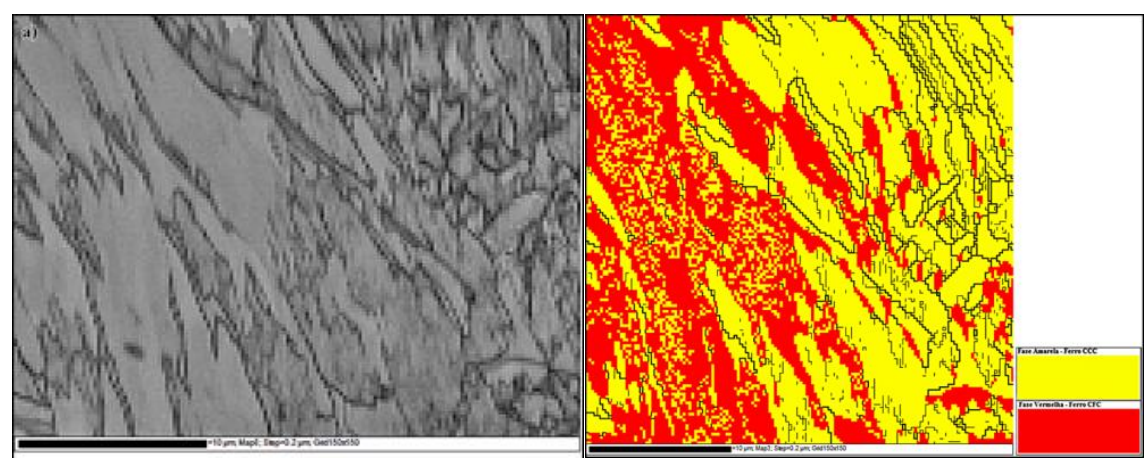

Figura 11. Análise de EBSD da região da zona fundida da amostra dissimilar F6. a) Imagem do padrão de qualidade (EBSD); b) Imagem do mapa de fases.

\section{DISCUSSÃO}

* Contribuição técnica ao 69ำ Congresso Anual da ABM - Internacional e ao 14ํㅡㄹ ENEMET - Encontro Nacional de Estudantes de Engenharia Metalúrgica, de Materiais e de Minas, 21 a 25 de julho de 2014, São Paulo, SP, Brasil. 


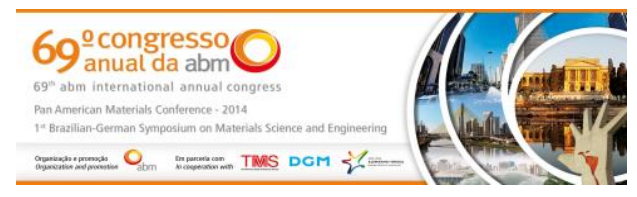

Segundo Lakshminarayanan et al. [8], a soldagem TIG utilizando corrente contínua apresenta uma maior entrada de calor quando comparado ao TIG pulsado, dessa forma, a variação referente à entrada de calor durante o processo de soldagem exerce influência no ciclo térmico e consequentemente, causa variações nas características microestruturais. Entretanto, neste caso ao utilizar corrente contínua constante e contínua pulsada durante a soldagem, não foi possível observar tal comportamento, visto que tanto na condição sem pulsação de corrente quanto nas condições de corrente pulsada para frequências de 2 e $4 \mathrm{~Hz}$ foram observadas transformações de austenita em martensita.

Porém, foi possível identificar alterações microestruturais em função da variação da frequência de pulsação. Ao aumentar a frequência de pulsação durante a soldagem com corrente contínua pulsada, verificou-se a formação de uma microestrutura típica duplex, formada somente por ferrita e austenita. Tal fato pôde ser confirmado através das análises realizadas que mostraram a formação de microestruturas austeníticas, ferríticas e martensíticas na zona fundida das amostras soldadas com corrente contínua constante $(0 \mathrm{~Hz})$ e aquelas soldadas com frequências de pulsação mais baixa (2 e $4 \mathrm{~Hz})$. Este comportamento foi atribuído à deflexão do arco em função da utilização de duas ligas com propriedades magnéticas distintas, o qual se mostrou menos intenso para maiores frequências de pulsação. Isto proporcionou uma composição mais balanceada entre as duas ligas para as condições de mais alta frequência de pulsação.

Conforme observado por Santos [9] apud Guimarães [10], a martensita encontrada nas zonas fundidas das amostras soldadas com frequências de 0,2 e $4 \mathrm{~Hz}$, é formada a partir da austenita e o seu surgimento pode estar relacionado ao resfriamento rápido que a austenita sofre após a soldagem e também pela menor quantidade de elementos austenitizantes na região.

Outra observação foi que diferentemente do observado por Mohandas e Reddy [11], não foi possível observar o provável efeito da fragmentação dos grãos colunares, atuando como agentes nucleantes para a solidificação de novos grãos. Verificou-se somente que a utilização de diferentes frequências de pulsação exercia influência na homogeneidade da composição microestrutural obtida.

\section{CONCLUSÕES}

De posse dos resultados obtidos para a soldagem dissimilar entre o aço inoxidável austenítico AISI 316L e AISI 444 utilizando o processo TIG autógeno com corrente pulsada, foi possível concluir que a soldagem realizada sofreu influência do fenômeno da deflexão magnética, que por sua vez influenciou a microestrutura obtida na zona fundida das amostras. Verificou-se que a zona fundida das amostras é formada preferencialmente por ferrita, martensita e austenita, sem a presença de fases secundárias, como Laves e carbonetos. Observou-se ainda que o aumento da frequência de pulsação atuou de forma a homogeneizar a zona fundida das amostras, evitando a formação martensítica, sendo a amostra considerada com microestrutura mais homogênea a soldada com frequência de $6 \mathrm{~Hz}$.

\section{Agradecimento}

\footnotetext{
* Contribuição técnica ao 69 Congresso Anual da ABM - Internacional e ao 14ํㅡㄹ ENEMET - Encontro Nacional de Estudantes de Engenharia Metalúrgica, de Materiais e de Minas, 21 a 25 de julho de 2014, São Paulo, SP, Brasil.
} 


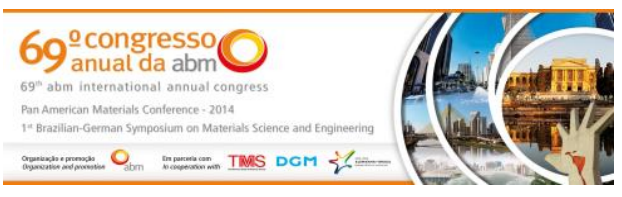

Aos Laboratórios de Engenharia de Soldagem e Caracterização de Materiais da Universidade Federal do Ceará. Aos órgãos de fomento CNPq, CAPES, FINEP, FUNCAP e ANP pelo suporte financeiro.

\section{REFERÊNCIAS}

1 Silva CC, Miranda HC, Sant'ana HB, Farias JP. Austenitic and ferritic Stainless steel dissimilar weld metal evaluation for applications as-coating in petroleum processing equipment. Materials \& Design. 2013;47:1-8.

2 Machado JPSE, Silva CC, Sobral-Santiago AVC, Sant'ana HB, Farias JP. Effect of temperature on the level of corrosion caused by heavy petroleum on AISI 304 and AISI 444 stainless steel. Materials Research. 2006;9(2):137-142.

3 Satyanarayana VV, Reddy GM, Mohandas T. Dissimilar metal friction welding of austenitic-ferritic stainless steels. Journal of Materials Processing, Technology. 2005;160:128-137.

4 Barros IF. Soldagem dissimilar do aço inoxidável ferrítico AISI 444 e do aço inoxidável austenítico AISI 316L por meio do processo TIG autógeno utilizando corrente pulsada [dissertação de mestrado]. Fortaleza: UFC; 2014.

5 Mendes EP. Estudo exploratório da soldagem de juntas dissimilares dos aços inoxidáveis AISI 316L e AISI 444 utilizando o processo TIG autógeno com corrente pulsada [monografia]. Fortaleza: UFC; 2012.

6 Brooks JA, Williams JC, Thompson AW. STEM Analysis of Primary Austenite Solidified Stainless Steel Welds. Metallurgical Transactions A. 1983;14(1):23-31.

7 Gooch TG. Welding martensitic stainless steels. Welding Institute Research Bulletin. 1977;18:343-349.

8 Lakshminarayanan AK, Shanmugam K, Balasubramanian V. Effect of autogenous arc welding process on tensile and impact properties of ferritic stainless steel joints. International Journal of Iron and Steel Research. 2009;16(1):62-68.

9 Santos CN. Aspectos cristalográficos da transformação martensítica de uma liga Fe 27\% Ni [tese]. Instituto Militar de Engenharia; 2008.

10 Guimarães JRC, Eckstein CB.. Correlação entre a microestrutura e reposta mecânica em misturas de austenita e martensita. In: Anais do Seminário sobre Metalurgia Física e Tratamentos Térmicos; 1983; São Paulo, Brasil. São Paulo: ABM; 1983.

11 Mohandas T, Reddy GM. A comparison of continuous and pulse current gas tungsten arc welds of an ultra high strength steel. Journal of Materials Processing and Technology. 1997;69(1):222-226.

* Contribuição técnica ao $69^{\circ}$ Congresso Anual da ABM - Internacional e ao 14ํㅡㄹ ENEMET - Encontro Nacional de Estudantes de Engenharia Metalúrgica, de Materiais e de Minas, 21 a 25 de julho de 2014, São Paulo, SP, Brasil. 